\title{
Effect of posttraining exposure to an aversive stimulus on retention
}

\author{
NORMAN M. WHITE and PETER LEGREE \\ McGill University, Montreal, Canada
}

\begin{abstract}
Rats were trained in a conditioned emotional response paradigm with two paired presentations of a tone and a mild shock. They were then removed from the training apparatus and given a single strong shock in a different cage. Twenty-four hours later, the rats were tested for the suppressive effect of the tone on drinking. The rats that had been trained in the paired condition and shocked immediately afterwards were significantly more suppressed than rats that had received the same training but had not been shocked afterwards. The paired, shocked rats were also more suppressed than rats that had been trained with unpaired tone-shock presentations and given the strong shock immediately afterwards and than rats that had received the strong shock $30 \mathrm{~min}$ after training. These data led to the conclusion that an aversive, or negatively reinforcing, event can improve retention in a retroactive, noncontingent manner. The implications of this finding for an understanding of the action of reinforcers, and for the organization of memory processes, are discussed.
\end{abstract}

The experimental paradigm in which memory for a particular event is influenced by treatments given just after the event occurs has permitted inferences about how memories are organized and stored in the brain, about events that influence memory, and about the role played by this process in controlling behavior. The best known posttraining treatment must be electroconvulsive shock, which disrupts memory in a time-dependent fashion (Duncan, 1949), lending support to the concept of the memory trace, which is created during acquisition and can be influenced during the posttraining period by various events. Other events that have been shown to improve or disrupt retention include treatments with various drugs (McGaugh \& Herz, 1972) and electrical stimulation of certain regions of the brain (Kesner \& Wilburn, 1974).

A number of theorists since Thorndike (1933) (e.g., Milner, 1970; Landauer, 1969; Routtenberg, 1975; Huston, Mueller, \& Mondadori, 1977) have suggested that reinforcers are among the class of events that can improve memory. Huston, Mondadori, and Waser (1974) tested this hypothesis by feeding hungry mice immediately after the training trial of a step-down passive avoidance task. On the day after training, the step-down latencies of the animals that were fed after training were significantly longer than those of control animals that were not fed. This result cannot be attributed to contingent reward of the step-down response by the food because such a process would have led to shorter, not longer, latencies. Therefore, the result suggests that food has a non-

This research was supported by grants from the Natural Sciences and Engineering Research Council of Canada and from Fonds FCAC, Province of Quebec. P. Legree is now at the University of Cleveland. N. M. White's mailing address is: Department of Psychology, McGill University, 1205 Dr. Penfield Ave., Montreal, P.Q., Canada H3A IB1. contingent memory-improving action, in addition to its contingent rewarding effect on behavior. Huston and his colleagues also showed that other positive, or rewarding, reinforcers can improve memory for a variety of different tasks (Huston et al., 1977; Mondadori, Waser, \& Huston, 1977). These findings were extended by Messier and White (1984), who found that drinking sucrose solutions immediately after training on a conditioned emotional response improved retention, but that drinking equally preferred saccharin solutions failed to improve retention. Two demonstrations that rewarding selfstimulation of the brain can improve retention (Coulombe \& White, 1980; Major \& White, 1978) are also consistent with this notion.

If reinforcers per se improve retention, there is no logical reason for the effect to be limited to positive, or rewarding, reinforcers: the question of whether or not negative, or aversive, reinforcers can influence memory is an empirical one. Mondadori et al. (1977) carried out a test of this question with the apparent expectation that an aversive posttraining event would disrupt retention. However, they found that immersing mice in ice water immediately after passive avoidance training had no clear effect on retention.

In the present report, we describe a demonstration of an improvement in retention by a posttraining, aversive reinforcing event.

\section{METHOD}

\section{Subjects}

The subjects were 34 male hooded rats, weighing between 240 and $350 \mathrm{~g}$ at the start of the experiment. They were housed 4 to a cage in a room with the lights on between 7 a.m. and 7 p.m. Food and water were continuously available, except as described in the procedure. 


\section{Apparatus}

The memory apparatus consisted of two cages constructed of Plexiglas and measuring $20 \times 20.5 \times 20.5 \mathrm{~cm}$. The floors of the cages were made of metal rods, and both cages had a loudspeaker on one of the side walls. The cage used for testing was painted black and had a drinking tube protruding through the wall on the side opposite to the loudspeaker. In this cage, the tube and the floor were connected with a drinkometer circuit that measured the number of 0.5 -sec periods during which the rats made contact with the drinking tube. The cage used for training was painted white and was illuminated with a 25 -W bulb. The floor rods were connected to a Grason-Stadler shocker. Both of these cages were housed inside sound-attenuating enclosures.

A third Plexiglas box $(20.5 \times 30.5 \times 19.5 \mathrm{~cm})$, with metal floor rods connected to the shocker, was used for posttraining shocks. This box had clear walls and was located in the same room as the memory apparatus, but was not inside an enclosure.

\section{Procedure}

The 34 rats were divided randomly among five groups: no treatment $(n=6)$, immediate shock $(n=11)$, unpaired $(n=5)$, delayed shock $(n=6)$, and preshock $(n=6)$. On each of the first 3 days of the experiment, the rats in all groups were handled for $2.3 \mathrm{~min}$. On Day 3, water was removed from their home cages. On Day 4 , the animals in all groups were preexposed to the black test cage. Each rat was placed into the cage for $10 \mathrm{~min}$ and allowed to drink freely. During this period, each rat heard five 10-sec tones (approximately $12 \mathrm{~dB}$ above ambient noise) at 2 -min intervals. Thirty minutes after the last rat in each home cage completed its preexposure session, the rats in that cage were given acceess to water for $30 \mathrm{~min}$.

On Day 5 , each rat in the preshock group was removed from its home cage and placed into the clear Plexiglas box, where it received a single 3-sec, 2-mA shock. Each tat in this group was immediately placed into the white training box. Each rat in the other four groups was removed from its home cage and placed directly into the training box. While in the training box, all rats heard two 10 -sec tones and received two 0.5 sec, 0.6-mA shocks, $1 \mathrm{~min}$ apart. Twenty-nine of the rats were trained in the "paired" condition. For these animals, the shocks were given during the last $0.5 \mathrm{sec}$ of the tones. The remaining five animals were trained in the "unpaired" condition. For these animals the shocks were given $20 \mathrm{sec}$ after the end of the tones.

The six animals in the preshock group were all trained in the paired condition. One minute after their last shock, they were returned to their home cages. One minute after the last training shock, each of the rats in the other four groups was removed from the training box. The rats in the no-treatment group were returned to their home cages. The rats in the immediate-shock group were placed into the postraining box and given a single shock ( $3.0 \mathrm{sec}, 2 \mathrm{~mA}$ ). They were then returned to their home cages. The rats in the unpaired group were treated identically. The rats in the delayed-shock group were returned to their bome cages for $30 \mathrm{~min}$ after training. They were then placed into the posttraining box and treated identically to the rats in the immediate-shock group.

Day 6 was the test day. The rats in all groups were treated identically. Each was placed into the black test cage and allowed to drink freely. When a rat had licked continuously for $10 \mathrm{sec}$ (no pauses of more than $2 \mathrm{sec}$ ), the tone came on for $10 \mathrm{sec}$. This $20-\mathrm{sec}$ period constituted a trial. Each rat completed 10 trials. Suppression ratios were calculated by dividing the number of 0.5 -sec periods during which the rat contacted the drinking tube while the tone was on by the number of contact periods that occurred during the 10-sec pre-CS periods when the tone was off.

\section{RESULTS}

The suppression ratio for each animal on each trial was transformed by taking one-half of its natural logarithm (Kruskal, 1978). The means of these ratios for the animals in each group increased monotonically over the 10 trials, suggesting extinction of the tone-shock association learned during training. To illustrate the differences in rates of extinction among the groups, the last five trials were selected for analysis, and the mean suppression ratios for these trials are presented in Figure 1.

A one-way analysis of variance showed that the groups did not differ significantly $[F(4,29)=0.860]$ on licking during the pre-CS periods. This suggests that the differences in the suppression ratios were primarily due to differences in licking during the CS periods. A one-way analysis of variance calculated on the ratio data showed a significant overall effect $[F(4,29)=4.206, p<.01]$. Comparisons between individual groups were made using $t$ tests based on the mean square error variance $(\mathrm{df}=$ 29) of the analysis.

The rats in the paired, immediate-shock group were significantly more suppressed than the rats in the notreatment group ( $\mathrm{t}=2.326, \mathrm{p}<.05$, two-tailed). The hypothesis that this increased suppression was due to a strengthened tone-shock association is supported by the fact that the animals in the paired, immediate-shock group were also significantly more suppressed than those in the unpaired group $(t=3.057, \mathrm{p}<.01$, two-tailed). The only difference in the pairing conditions for these two groups was the relationship between the tones and the shocks. The posttraining shock was the same and occurred in the same relationship to the training session for the two groups. Therefore, it is highly likely that the difference in suppression in the two groups was caused by a difference in the strength of the animals' tone-shock associations.

The rats in the immediate-shock group were also significantly more suppressed than the rats in the delayed group $(t=1.890, p<.05$, one-tailed). It is noteworthy that the 30-min delay that produced this decrement in suppression was short relative to the delays required to

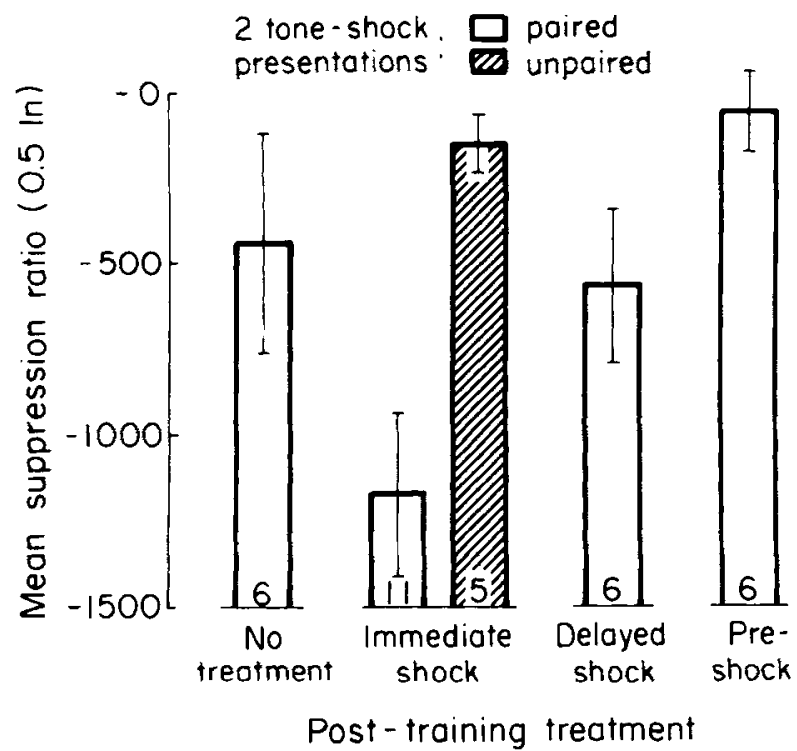

Figure 1. Mean suppression ratios for the rats in each of the five experimental groups. The vertical lines at the top of each bar are standard errors of the means. The figures at the bottom of each bar show the number of subjects in each group. 
produce similar decrements in our previous experiments on the effect of posttraining rewarding events on memory. These delays ranged up to $2 \mathrm{~h}$ for sucrose solutions (Messier \& White, 1984) and $4 \mathrm{~h}$ for self-stimulation (Coulombe \& White, 1980). This may account for the fact that the decrement observed in the present experiment was relatively small. This decrement suggests that the effect of the posttraining shock interacted with a process that persisted for a limited duration after the training session, as suggested by various theories of memory consolidation (Hebb, 1972; McGaugh \& Herz, 1972). The difference between these two groups also provides evidence that the effect produced by posttraining shock in this experiment was due to a retroactive effect on processes initiated during training, and not to a proactive influence on the animals' behavior during the test session.

Finally, there was no significant difference between the mean suppression ratios of the rats in the preshock and the no-treatment groups $(\mathrm{t}=0.674)$. Moreover, the rats in the immediate shock group were signifiantly more suppressed than the rats in the preshock group $(t=3.508$, $\mathrm{p}<.01$, two-tailed). This result must be interpreted with caution because of the possibility that the reinforcing shock may have resulted in stress-induced analgesia, which would have prevented formation of a tone-shock association during training. Using a radiant heat tail-flick test, Chance and Rosencrans (1979) observed analgesia after a single $15-\mathrm{sec}, 0.9-\mathrm{mA}$ footshock. We have no direct evidence that this phenomenon occurred in our experiment, but it cannot be ruled out. To the extent that it can be assumed that this effect did not occur, the data for this group suggest that the tone-shock association must already have been formed for the aversive event to have its effect; mere contiguity with the training session was not sufficient to increase suppression.

\section{DISCUSSION}

The data of the present study show that the presentation of an aversive event during the period immediately after conditioned emotional response training can improve memory for that training. The data also permit the conclusion that this effect was a noncontingent one that acted retroactively to strengthen a tone-shock association that had already been formed. These findings have implications in two areas: the role of reinforcers in controlling behavior and the organization of the memory process itself.

Although previous theoretical formulations (Huston et al., 1977; Routtenberg, 1975) and experiments (Coulombe \& White, 1980; Huston et al., 1974; Huston et al., 1977; Major \& White, 1978; Messier \& White, 1983; Mondadori et al., 1977) have contemplated and demonstrated the proposition that rewarding, or positive, reinforcers can improve memory, the present data show clearly that a frankly aversive event can have a similar effect. This finding, taken together with those involving rewarding events, has implications for an understanding of how reinforcers influence behavior.
The affective properties of reinforcers, as measured by their contingent rewarding or punishing effects, have been extensively studied and documented. The results of studies showing that reinforcers also have a noncontingent memory-improving action suggest that this latter function may be independent of their contingent action. This idea is illustrated in an experiment by Messier and White (1984), who showed that drinking sucrose after CER training improved retention of a tone-shock association, but that drinking an equally preferred saccharin solution had no such effect. Since both solutions were equally preferred, it can be argued that their contingent rewarding effects were the same; but the fact that they had different effects on retention means that their noncontingent memory-improving properties were not the same. This notion of a separation between the affective and the memory-improving properties of reinforcers is supported by the results of the present experiment, in which an aversive event was shown to have the same memoryimproving action as rewarding events such as eating food, drinking sucrose solutions, or a session of self-stimulation. The fact that events that are opposite in affective sign have similar effects on retention suggests that it will be profitable to investigate further the possible separation of the neural substrates of the affective and the memoryimproving actions of reinforcers.

The concept of arousal was advanced as a possible explanation of the effect of reinforcement on memory by Hebb (1972). He suggested that when a particular level of arousal was attained during the posttraining period, certain neural processes were optimized for the formation of interneuronal connections. Hebb argued that all reinforcing events produced an optimum level of arousal. However, the precise degree of arousal required to produce these effects has never been specified, and it is difficult to imagine that the level of arousal observed when an animal drinks a sucrose solution and the level observed when an animal receives a 3-mA shock are equivalent. This raises the question of whether the optimum-level concept is a useful explanation of the results of posttraining treatment experiments.

An extension of Hebb's theory has been proposed by Gold and McGaugh (1975). These authors suggest that biologically relevant stimuli (stimuli that produce affective arousal; Young, 1961) result in certain neural and humoral events that produce improvements in memory. Since both rewarding and aversive stimuli produce affective arousal, this theory can account for the results observed with both types of reinforcers. Before this explanation can be accepted, however, it will be necessary to specify the neural and humoral events that produce this effect.

The fact that an obviously aversive event has been shown to improve retention has implications for the interpretation of experiments in which other posttraining treatments have been shown to have similar effects. One example is the finding that posttraining injections of amphetamine improve retention (Doty \& Doty, 1966; Krivanek \& McGaugh, 1969). It is also known that this 
drug produces a conditioned taste aversion (Carey, 1973; Goudie, 1979), implying that it has aversive properties. This raises a question that will have to be answered by future research: Is amphetamine's memory-improving action related to its aversive affective consequences?

A similar question can be asked with regard to the memory-improving action of vasopressin (de Weid, 1971; de Weid \& Bohus, 1979). In a recent study, Ettenberg, Van der Kooy, Le Moal, Koob, and Bloom (1983) found that vasopressin had aversive qualities. These authors suggested that these aversive properties might account for the memory-improving action of vasopressin. In support of this notion, they showed that posttraining injections of lithium chloride (another presumably aversive event) had the same effect as vasopressin on performance in a waterfinding task. The present data, showing that a different kind of aversive event can improve retention, supports this suggestion.

\section{REFERENCES}

Carey, R. J. (1973). Acquired aversion to amphetamine solutions. Pharmacology, Biochemistry and Behavior, 1, 227-229.

Chance, W. T., \& Rosencrans, J. A. (1979). Lack of effect of naloxone on autonanalgesia. Pharmacology, Biochemistry and Behavior, 11, 643-646.

Coulombe, D., \& White, N. M. (1980). The effect of post-training lateral hypothalamic self-stimulation on aversive and appetitive classical conditioning. Physiology \& Behavior, 25, 267-272.

DE WEID, D. (1971). Long term effects of vasopressin on the maintenance of a conditioned avoidance response in rats. Nature, 232, 58-60.

DE WEID, D., \& BoHUS, B. (1979). The modulation of memory processes by neuropeptides of hypothalamic-neurohypophyseal origin. In M. A. B. Brazier (Ed.), Brain mechanisms in memory and learning (pp. 139-149). New York: Raven.

DoTY, B., \& DoTY, L. (1966). Facilitating effects of amphetamine on avoidance conditioning in relation to age and problem difficulty. Psychopharmacology, 9, 234-241.

Duncan, C. P. (1949). The retroactive effect of electroshock on learning. Journal of Comparative and Physiological Psychology, 42, 32-44.

Ettenberg, A., Van der Kooy, D., Le Moal, M., Koob, G. F., \& BLoom, F. E. (1983). Can aversive properties of (peripherally injected) vasopressin account for its putative role in memory? Behavioral Brain Research, 7, 331-350.
Gold, P. E., \& MCGAUGH, J. L. (1975). A single trace, two-process view of memory storage processes. In D. Deutsch \& J. A. Deutsch (Eds.), Short term memory. New York: Academic Press.

GoudiE, A. J. (1979). Aversive stimulus properties of drugs. Neuropharmacology, 13, 971-979.

HeBB, D. O. (1972). A textbook of psychology (3rd ed.), New York: Wiley.

Huston, J. P., Mondadori, C., \& Waser, P. G. (1974). Facilitation of learning by reward of post-trial memory processes. Experientia, 30, 1038-1040.

Huston, J. P., Mueller, C. C., \& Mondadori, C. (1977). Memory facilitation by post-trial hypothalamic stimulation and other reinforcers: A central theory of reinforcement. Biobehavioral Reviews, 1, 43-150.

KESNER, R. P., \& WILBURN, M. W. (1974). A review of electrical stimulation of the brain in the context of learning and retention. Behavioral Biology, 10, 259-293.

KrIVANEK, J., \& McGaUGh, J. L. (1969). Facilitating effects of preand post-training amphetamine on discrimination learning in mice. Agents and Actions, 1, 36-42.

KRUSKAL, J. B. (1978). Transformations of data. In W. H. Kruskal \& J. M. Tanur (Eds.), International encyclopedia of statistics (Vol. 2, pp. 1044-1056). New York: The Free Press.

LANDAuer, T. K. (1969). Reinforcement as consolidation. Psychological Review, 76, 82-96.

MAJOR, R., \& WHITE, N. (1978). Memory facilitation by self-stimulation reinforcement mediated by the nigro-neostriatal bundle. Physiology \& Behavior, 20, 723-733.

McGaugh, J. L., \& Herz, M. J. (1972). Memory consolidation. San Francisco: Albion.

Messier, C., \& White, N. (1984). Contingent and non-contingent actions of sucrose and saccharin reinforcers: Effects on taste preference and memory. Physiology \& Behavior, 32, 195-203.

Milner, P. M. (1970). Physiological psychology. New York: Reinhart and Winston.

Mondadori, C., Waser, P. G., \& Huston, J. P. (1977). Time dependent effects of post-trial reinforcement, punishment or ECS on passive avoidance learning. Physiology \& Behavior, 18, 1103-1109.

ROUTTENBERG, A. (1975). Intracranial self-stimulation pathways are substrate for memory consolidation. In M. R. Jones ( Ed.), Nebraska symposium on motivation. Lincoln: University of Nebraska.

ThorNDike, E. L. (1933). A theory of the action of the aftereffects of a connection upon it. Psychological Review, 40, 434-439.

Young, P. T. (1961). Motivation and emotion. New York: Wiley.

(Manuscript received September 19, 1983; revision accepted for publication June 26,1984 .) 